\title{
Preoperative Upper Gastrointestinal Endoscopy Prior to Sleeve Gastrectomy: To Do, or Not to Do
}

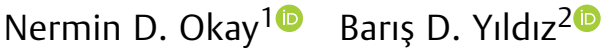 \\ ${ }^{1}$ Department of General Surgery, Ankara City Hospital, Ankara, \\ Turkey \\ 2 Department of General Surgery, Faculty of Medicine, Yozgat Bozok \\ University, Yozgat, Turkey \\ J Health Allied Sci ${ }^{\mathrm{NU}}$ 2022;12:423-426.
}

\begin{abstract}
Keywords

- endoscopy

- gastrointestinal stromal tumor

- obesity

- sleeve gastrectomy

There is controversy about the requirement of preoperative upper gastrointestinal (GI) endoscopy for sleeve gastrectomy patients. The aim of this study is to understand the necessity of a preoperative upper $\mathrm{Gl}$ endoscopy before sleeve gastrectomy. In this study, the incidental findings encountered in sleeve gastrectomy pathology specimens of a cohort of patients were analyzed. A total of 270 patients who had sleeve gastrectomy at Ankara Numune Teaching Hospital, General Surgery Clinic, between 2011 and 2016 were evaluated. Histopathological examination of sleeve gastrectomy specimens was performed. Chronic gastritis in $76.6 \%$ and intestinal metaplasia in $4.1 \%$ of patients were observed. A GI stromal tumor was found in one male patient. Also, an active gastric ulcer was detected in one patient. Only 13 (4.9\%) out of 270 patients had a postoperative pathology needing follow-up. None of our findings would have an impact of changing the surgical approach. Therefore, the results of this study suggested that application of a preoperative $\mathrm{Gl}$ endoscopy is not necessary prior to sleeve gastrectomy in patients without upper $\mathrm{Gl}$ symptoms.
\end{abstract}

\author{
Address for correspondence Nermin D. Okay, MD, Ankara City \\ Hospital, General Surgery Clinic, Ankara 06230, Turkey \\ (e-mail: nermindamla_72@hotmail.com).
}

\section{Introduction}

According to the World Health Organization (WHO), obesity is defined as excessive and abnormal accumulation of fat in the body causing a health risk. ${ }^{1}$ Fat accumulation is calculated as body mass index (BMI: weight $[\mathrm{kg}] /$ height $^{2}[\mathrm{~m}]$ ). The National Institute of Health defined morbid obesity as BMI higher than $40 \mathrm{~kg} / \mathrm{m}^{2}$ or BMI higher than $35 \mathrm{~kg} / \mathrm{m}^{2}$ with obesity-related health conditions. ${ }^{2}$

In 2015, the global rate of obesity was $39 \%$ of the population in the world, and the prevalence of obesity was mostly higher in women than in men. ${ }^{3}$ Obesity mainly results from imbalance between energy intake and consumption. Many factors such as genetic, metabolic, hormonal, hypothalamic, psycho- logical, inadequate physical activity, and low socioeconomic level have roles in obesity. ${ }^{2}$ Complications of obesity include hyperinsulinemia, insulin resistance, diabetes mellitus, hypertension, sleep apnea syndrome, osteoarthritis, gallstone formation, chronic kidney disease, cardiovascular diseases, and cancers such as colon, prostate, and endometrium. ${ }^{4}$

The goal in the treatment of obesity is to decrease the body weight via supplying the adequate basic nourishment to decrease the risks of obesity related morbidity and mortality. Methods for the treatment of obesity should be multidisciplinary and include diet, exercise, medical treatment, and surgical strategies. ${ }^{5}$

In recent years, bariatric surgery and especially sleeve gastrectomy gained popularity. The patients should be published online

February 18, 2022
DOI https://doi.org/ $10.1055 / \mathrm{s}-0042-1743190$. ISSN 2582-4287.

\footnotetext{
(C) 2022. Nitte (Deemed to be University). All rights reserved. This is an open access article published by Thieme under the terms of the Creative Commons Attribution-NonDerivative-NonCommercial-License, permitting copying and reproduction so long as the original work is given appropriate credit. Contents may not be used for commercial purposes, or adapted, remixed, transformed or built upon. (https://creativecommons.org/ licenses/by-nc-nd/4.0/)

Thieme Medical and Scientific Publishers Pvt. Ltd., A-12, 2nd Floor, Sector 2, Noida-201301 UP, India
} 
Table 1 The findings in the pathological specimens of sleeve gastrectomy patients

\begin{tabular}{|l|l|l|l|l|l|l|l|l|}
\hline \multicolumn{2}{|c|}{} & \multicolumn{2}{|l|}{ Type of pathology } & \multirow{2}{*}{ Total } \\
\cline { 3 - 9 } \multicolumn{2}{|c|}{} & $\begin{array}{l}\text { Regular gastric } \\
\text { tissue }\end{array}$ & $\begin{array}{l}\text { Chronic } \\
\text { gastritis }\end{array}$ & $\begin{array}{l}\text { Intestinal } \\
\text { metaplasia }\end{array}$ & Active gastric ulcer & GIST & \\
\hline \multirow{3}{*}{ Gender } & \multirow{2}{*}{ Male } & $n$ & 7 & 34 & 3 & 0 & 1 & 45 \\
\cline { 3 - 10 } & $\%$ & 15.6 & 75.6 & 6.7 & 0 & 2.2 & 100.0 \\
\cline { 3 - 10 } & \multirow{2}{*}{ Female } & $n$ & 43 & 173 & 8 & 1 & 0 & 225 \\
\cline { 3 - 9 } & $\%$ & 19.1 & 76.8 & 3.6 & 0.5 & 0.0 & 100.0 \\
\hline \multirow{3}{*}{ Total } & $n$ & 50 & 207 & 11 & 1 & 0.4 & 100.0 \\
\cline { 3 - 9 } & $\%$ & 18.5 & 76.6 & 4.1 & 0.4 & 0.4 \\
\hline
\end{tabular}

Abbreviation: GIST, gastrointestinal stromal tumor.

evaluated in terms of comorbidities and postoperative adaptation. They should also be undertaken to psychological and physical evaluation, laboratory tests, and imaging. There is still not a consensus on the necessity of the preoperative evaluation of the stomach (i.e., esophageal-gastro duodenoscopy and contrast radiography) in workup of sleeve gastrectomy. The European Association of Endoscopic Surgery (EAES) recommends one of these two imaging methods for all patients who are bariatric surgery candidates. However, according to the American Society for Metabolic and Bariatric Surgery (ASMBS), preoperative imaging is not necessary for patients without a complaint. ${ }^{6}$

The aim of this study was analysis of the incidental findings encountered in sleeve gastrectomy pathology specimens and defining whether preoperative endoscopy is necessary.

\section{Methods}

This study was conducted in the Ankara Numune Teaching Hospital General Surgery Clinic, Turkey, and approved by this hospital's Ethical Committee (approval number: E-16-1153). All patients who underwent sleeve gastrectomy due to obesity in general surgery clinic between 2011 and 2016 years were included in the study. Their pathology reports were reviewed and accompanying incidental pathologies were evaluated.

The decision for operation of patients was taken according to "The Practical Guide for Identification, Evaluation, and Treatment of Overweight and Obesity in Adults" (NHLBI 2000). All patients were under the control of a dietician. Following the preoperative blood tests and radiological scanning, routine consultations of internal diseases, pulmonary diseases, endocrinology, dietician, and psychiatry were done. The informed consent was taken from all patients. Preoperative respiratory exercises and prophylactic anticoagulation treatment with low molecular weight heparin were initiated as patient was hospitalized. All operations were performed by the surgeons working at the General Surgery Clinic of the hospital.

The study included 45 males and 225 females (270 total) patients who underwent sleeve gastrectomy. The files of the patients were evaluated retrospectively, and their gender, age, height, preoperative weight, BMI, pathology reports, and preoperative endoscopy findings were analyzed. The data were analyzed using SPSS 22.0 program.

\section{Results}

The age of the patients ranged between 15 and 64 years with a mean of $39.3 \pm 10.8$ years. The BMI values ranged between 33.18 and $97.70 \mathrm{~kg} / \mathrm{m}^{2}$ with a mean of $47.74 \pm 6.9 \mathrm{~kg} / \mathrm{m}^{2}$. The investigation of pathological specimens showed chronic gastritis in $77 \%$ of patients (-Table $\mathbf{1}$ ). A gastrointestinal (GI) stromal tumor (GIST) was observed in one male patient. The rate of intestinal metaplasia among males was $6.7 \%$ and it was 3.6\% among females. Of note, one patient with postoperative stapler line leak had active ulceration on gastric mucosa in pathology specimen.

Out of 270 patients, preoperative upper GI endoscopy was applied to 144 patients. Thirty-one patients had normal findings, 58 patients had gastritis, and 37 patients had bulbitis. Additionally, 11 patients had hiatal hernia together with gastroesophageal reflux disease (GERD), six patients had only GERD, and one patient had adjustable gastric band in situ.

The 11 patients with pathological findings requiring postoperative follow-up, that is, intestinal metaplasia and GIST, were evaluated. Six out of 11 patients who had intestinal metaplasia in their pathological examination did not have preoperative upper GI endoscopy. Of the five patients who had upper GI endoscopy preoperatively, two had normal endoscopic findings, one had gastritis, one had bulbitis, and one had hiatal hernia. Intestinal metaplasia was not detected preoperatively in these five patients. The single patient whose pathological examination showed GIST did not have GI endoscopy preoperatively. The GIST patient was a 55-yearold male without an additional comorbidity. His BMI was $46 \mathrm{~kg} / \mathrm{m}^{2}$. According to the pathology report, a rigid nodular lesion was observed measuring up to $0.6 \mathrm{~cm}$ in diameter on the serosal surface, macroscopically. The tumor was located through the muscular layer and the mitosis count was $2 / 50$ high-power field (HPF), microscopically. The CD117 and CD34 were found to be positive immunohistochemically. The $\mathrm{K}_{\mathrm{i}}-67$ proliferation index was 1 to $2 \%$.

Chronic gastritis was found in $75 \%$ of the patients who had postoperative stapler line leak ( - Table 2 ). Prior to sleeve 
Table 2 Pathological findings in sleeve gastrectomy patients with a leak

\begin{tabular}{|l|l|l|l|l|}
\hline & $\boldsymbol{n}$ & \% & Valid percent & Cumulative percent \\
\hline Normal gastric tissue & 1 & 12.5 & 12.5 & 12.5 \\
\hline Active gastric ulcer & 1 & 12.5 & 12.5 & 25 \\
\hline Chronic gastritis & 6 & 75 & 75 & 100.0 \\
\hline Total & 8 & 100.0 & 100.0 & \\
\hline
\end{tabular}

Table 3 Pathological findings in the sleeve gastrectomy patients according to their previous obesity operation (i.e., IGB, LAGB, and RSG) status

\begin{tabular}{|c|c|c|c|c|c|}
\hline & & & \multicolumn{2}{|c|}{ Previous obesity operation } & \multirow[t]{2}{*}{ Total } \\
\hline & & & No & Yes & \\
\hline \multirow[t]{12}{*}{ Pathology } & \multirow[t]{2}{*}{ Normal stomach tissue } & $n$ & 42 & 8 LAGB & 50 \\
\hline & & $\%$ & 17.0 & 34.8 & 18.5 \\
\hline & \multirow[t]{4}{*}{ Chronic gastritis } & \multirow[t]{3}{*}{$n$} & \multirow[t]{3}{*}{192} & 13 LAGB & \multirow[t]{3}{*}{207} \\
\hline & & & & $1 \mathrm{IGB}$ & \\
\hline & & & & 1 RSG & \\
\hline & & $\%$ & 77.7 & 65.2 & 76.6 \\
\hline & \multirow[t]{2}{*}{ Intestinal metaplasia } & $n$ & 11 & 0 & 11 \\
\hline & & $\%$ & 4.5 & 0.0 & 4.1 \\
\hline & \multirow[t]{2}{*}{ GIST } & $n$ & 1 & 0 & 1 \\
\hline & & $\%$ & 0.4 & 0.0 & 0.4 \\
\hline & \multirow[t]{2}{*}{ Active gastric ulcer } & $n$ & 1 & 0 & 1 \\
\hline & & $\%$ & 0.4 & 0.0 & 0.4 \\
\hline \multirow{2}{*}{\multicolumn{2}{|c|}{ Total }} & $n$ & 247 & 23 & 270 \\
\hline & & $\%$ & 100.0 & 100.0 & 100.0 \\
\hline
\end{tabular}

Abbreviation: GIST, gastrointestinal stromal tumor. IGB, intragastric balloon; LAGB, laparoscopic adjustable gastric banding; RSG, resleeve gastrectomy.

gastrectomy, 23 patients had obesity operations, and 15 (65.2\%) of them had chronic gastritis. Of these 15 patients, 13 had previous laparoscopic adjustable gastric banding operation, 1 had intragastric balloon operation, and 1 had resleeve gastrectomy operation. None of these patients had intestinal metaplasia or GIST (-Table $\mathbf{3}$ ).

Eight of the patients with previous obesity operation were received preoperative GI endoscopy. Five patients had normal findings. One patient had adjustable gastric band in situ, one patient with previous intragastric balloon had gastritis, and one patient with resleeve gastrectomy had hiatal hernia together with GERD.

\section{Discussion}

To date, there is not a consensus on the requirement of upper GI endoscopy as a preoperative evaluation for the patients planned to undergo sleeve gastrectomy. According to the ASMBS medical guidelines, preoperative upper GI endoscopy is not required for the sleeve gastrectomy patients. ${ }^{7}$ The relation of postoperative abnormal histopathological findings to the BMI and age is still a contentious topic. However, the EAES suggests a routine preoperative upper GI endoscopic evaluation. ${ }^{8}$

In the present study, pathological findings of the patients who underwent sleeve gastrectomy were analyzed, and the requirement of a preoperative upper GI endoscopic evaluation was investigated. There was only one incidental GIST which did not alter the surgical strategy. GISTs develop from the submucosa and have low possibility of identification via upper GI endoscopy. Moreover, a GIST may not be detected during surgery. Roshanravan et $\mathrm{al}^{9}$ did not observe a mass during the sleeve gastrectomy operation of a 45 -year-old female, while GIST was detected in postoperative pathological examination. Finnell et $\mathrm{al}^{10}$ found $2 \%$ unexpected pathologic lesions during laparoscopic bariatric surgery and Sanchez et $\mathrm{al}^{11}$ found gastric GISTs as $0.8 \%$ during surgery upon investigation of the stomach before partitioning.

There is controversy about the requirement of preoperative GI endoscopy for sleeve gastrectomy patients. In the study of Sharaf et al, ${ }^{12}$ covering 195 patients, application of a preoperative upper GI endoscopy was suggested for the sleeve gastrectomy patients even when they were asymptomatic. Similarly, the study of Muñoz et al, ${ }^{13}$ including 626 patients, 
suggested preoperative GI endoscopic evaluation since the pathological findings change the surgical approach. On the other hand, the results of Korenkov et al $^{14}$ emphasized that the application of preoperative GI endoscopy is not necessary for the asymptomatic patients. Ghassemian et $\mathrm{al}^{15}$ applied preoperative GI radiography to 657 bariatric surgery patients but the pathological findings did not change the surgical approach. Hence, they concluded that a preoperative evaluation is not required because it is not cost-effective. Due to the lack of a consensus on preoperative endoscopy set by guidelines, some of the surgeons preferred omitting endoscopy but some chose to do it regularly in our study.

The pathologies which might change intraoperative management, such as cancer, were not seen in our dataset. In such a situation, it is obvious that a more radical surgery rather than obesity surgery would be performed. None of the other incidental findings hinder the application of sleeve gastrectomy. The application of preoperative GI endoscopy is suggested in situations requiring an additional surgical operation such as hiatal hernia, Barrett's esophagus, or gastric adenocancer. ${ }^{16}$

\section{Limitations}

The limitation of our study is inadequate reporting the Helicobacter pylori organisms inside the specimens which have a role in gastritis and ulcer formation. Secondary to this underreporting, we cannot comment on relation between complications and presence of this organism. The second limitation of our study is that the surgical procedures were performed by different surgeons with varied experience thus outcomes were not standardized.

\section{Conclusion}

Our findings suggested that a routine GI endoscopy is not necessary prior to sleeve gastrectomy. In this condition, the benefits of not doing endoscopy are reducing the cost, as well as not exposing the patient to anesthesia and an invasive intervention (i.e., endoscopy). In case of symptomatic patients with hiatal hernia and/or GERD, the GI endoscopy is suggested. The high rate of chronic gastritis in patients with postoperative leaks might suggest initiation of an antiulcer medication; however, studies with large data are required to evaluate cost effectiveness and efficacy of the process.

\section{Ethical Approval}

This study was approved by Ankara Numune Teaching Hospital Ethical Committee (approval number: E-161153) and performed in accordance with the ethical standards laid down in the 1964 Declaration of Helsinki and its later amendments.
Conflict of Interest

None declared.

\section{References}

1 Abdelaal M, le Roux CW, Docherty NG. Morbidity and mortality associated with obesity. Ann Transl Med 2017;5(07):161

2 Schauer PR, Schirmer B. The surgical management of obesity. Brunicardi FC, Andersen DK, Billiar TR, et al, eds. Schwartz's Principles of Surgery, 10th ed. McGraw-Hill Companies Inc.; 2015

3 Chooi YC, Ding C, Magkos F. The epidemiology of obesity. Metabolism 2019;92:6-10

4 Afshin A, Forouzanfar MH, Reitsma MB, et al; The Global Burden of Disease (GBD) 2015 Obesity Collaborators. Health effects of overweight and obesity in 195 Countries over 25 years N Engl J Med 2017;377(01):13-27 PubMed

5 Wirth A, Wabitsch M, Hauner $\mathrm{H}$. The prevention and treatment of obesity. Dtsch Arztebl Int 2014;111(42):705-713

6 Tichansky DS, Sudan R. Preoperative care of the bariatric patient. Nguyen NT, Blackstone RP, Morton JM, et al, eds. The ASMBS Textbook of Bariatric Surgery. New York, NY: Springer-Verlag; 2015

7 Mechanick JI, Kushner RF, Sugerman HJ, et al; American Association of Clinical Endocrinologists Obesity Society American Society for Metabolic \& Bariatric Surgery. American Association of Clinical Endocrinologists, The Obesity Society, and American Society for Metabolic \& Bariatric Surgery medical guidelines for clinical practice for the perioperative nutritional, metabolic, and nonsurgical support of the bariatric surgery patient. Obesity (Silver Spring) 2009;17(Suppl 1):S1-S70, v

8 Sauerland S, Angrisani L, Belachew M, et al; European Association for Endoscopic Surgery. Obesity surgery: evidence-based guidelines of the European Association for Endoscopic Surgery (EAES). Surg Endosc 2005;19(02):200-221

9 Roshanravan R, Esfahani MH, Moslemi S, Hosseini SV, Gabash KM. Gastric gastrointestinal stromal tumor (GIST) incidentally found after laparoscopic sleeve gastrectomy: a case report. Ann Colorectal Res. 2014;2:e24855

10 Finnell CW, Madan AK, Ternovits CA, Menachery SJ, Tichansky DS. Unexpected pathology during laparoscopic bariatric surgery. Surg Endosc 2007;21(06):867-869

11 Sanchez BR, Morton JM, Curet MJ, Alami RS, Safadi BY. Incidental finding of gastrointestinal stromal tumors (GISTs) during laparoscopic gastric bypass. Obes Surg 2005;15(10):1384-1388

12 Sharaf RN, Weinshel EH, Bini EJ, Rosenberg J, Sherman A, Ren CJ. Endoscopy plays an important preoperative role in bariatric surgery. Obes Surg 2004;14(10):1367-1372

13 Muñoz R, Ibáñez L, Salinas J, et al. Importance of routine preoperative upper GI endoscopy: why all patients should be evaluated? Obes Surg 2009;19(04):427-431

14 Korenkov M, Sauerland S, Shah S, Junginger T. Is routine preoperative upper endoscopy in gastric banding patients really necessary? Obes Surg 2006;16(01):45-47

15 Ghassemian AJ, MacDonald KG, Cunningham PG, et al. The workup for bariatric surgery does not require a routine upper gastrointestinal series. Obes Surg 1997;7(01):16-18

16 Parikh M, Liu J, Vieira D, et al. Preoperative endoscopy prior to bariatric surgery: a systematic review and meta-analysis of the literature. Obes Surg 2016;26(12):2961-2966 